\title{
The Association between Sex Hormones and Developmental Stuttering Disorder: A Systematic Review
}

\author{
Hossein Shayeste Yekta ${ }^{1}$, Farya Fakoori ${ }^{1}$, Hiwa Mohammadi ${ }^{2} \&$ Siavash Vaziri $^{2}$ \\ ${ }^{1}$ Students Research Committee, Kermanshah University of Medical Sciences, Kermanshah, Iran \\ ${ }^{2}$ Kermanshah University of Medical Sciences, Kermanshah, Iran \\ Correspondence: Hiwa Mohammadi, Kermanshah University of Medical Sciences, Kermanshah, Iran. E-mail: \\ Hiwa.mohamadi@gmail.com
}

Received: March 29, 2020

Accepted: May 19, 2020

Online Published: November 30, 2020

doi:10.5539/jmbr.v10n1p185

URL: https://doi.org/10.5539/jmbr.v10n1p185

\begin{abstract}
Stuttering is a male-biased speech motor control disorder that lead to disruption in the rhythm of speech. The effect of sex on development of stuttering is well known; males are more susceptible to and less recovered from stuttering than female. Sex hormones have been studied as a main accused factor for this gender dependency of the disorder. The aim of this systematic review is to navigate the extent of previous research about the relationship of developmental stuttering and sex hormones. Toward these ends, a comprehensive, electronic review of past concepts regarding the relationship of stuttering with sex hormones and digit ratio as an indirect index for fetal testosterone exposure, in Scopus, Science Direct, PubMed, Medline, Embase, and Cochrane database was carried out to identify potential studies for the review. Inclusion criteria were original quantitative research, written in English, used human subjects and published from 2000 through 2020. Findings were mixed, although potential patterns were identified. There were methodological limitations such as small participant numbers, in the targeted population in this review research. The findings from this current study add to the growing body of evidence demonstrating that sex hormone have a significant association with stuttering.
\end{abstract}

Keywords: Sex hormones, developmental stuttering disorder, review

\section{Introduction}

Developmental stuttering is a multifactorial speech disorder defined as a disturbance in the normal verbal fluency characterized by involuntary frequent repetitions, blocks, and prolonged speech sounds. The prevalence of stuttering is about 5\% during childhood but reduced to $1 \%$ among adults due to spontaneous recovery (De Oliveira et al., 2013). The etiology of developmental stuttering is unknown but epidemiological data put forward the role of sex steroid hormone specially androgen. There is a higher incidence of stuttering in males than in females with a male to female ratio of $2: 1$. But the ratio is increased to $4: 1$ because of more recovery among females than males (Drayna et al., 1999).

Sex hormones may consider as one of the reasons underlying this gender difference in stuttering. Testosterone is one of the most powerful androgens secreted from the testis and adrenal gland. During early human development, there are two periods during which the male brain is exposed to higher levels of androgen than the female brain. The initial period begins at 8-10 weeks of gestation, with testosterone levels of males reaching a peak at about 13-15 weeks (Migeon \& Wisniewski, 1998). The second surge of testosterone elevation in males occurs during the initial six post-natal months. Exposure of the brain to testosterone and estradiol in early infancy has been reported to affect the language development and has been associated to left- some neurodevelopmental conditions (Smail et al., 1981). Fetal testosterone secreted by the gonads may influence other body structures, including the face fingers, and toes (Burris \& Nelson, 2007). It has been reported that testosterone plays a role in sexual activity, libido, social behaviors, aggression, cognitive functions, sleep regulation, and well-being in both males and females. Previous studies demonstrated that many predominantly male conditions might associated to a high level of fetal testosterone, which delays left hemisphere growth, causes right-hemisphere dominance for speech and language, and results in left-handedness. (Zitzmann, 2006; Barrett-Connor et al., 1999). Two prominent theories address the influence of fetal testosterone exposure on cerebral lateralization; Geschwind and Galaburda (1987) proposed exposure to higher levels of fetal testosterone during critical periods of prenatal neurodevelopment shifts development of structures sub serving certain functions, such as language, predominantly to the right hemisphere 
(Geschwind \& Galaburda 1987). They further suggested that the influence of prenatal testosterone exposure on left-hemisphere growth retardation would be more apparent in men. A second theory, the callosal hypothesis put forward by Witelson and Nowakowski, suggests that in men, higher concentrations of fetal testosterone increases axonal pruning in the corpus callosum, which leads to a more pronounced typical lateralization of functions (Witelson and Nowakowski, 1991).

The 2D:4D ratio is a recent marker proposed to correlate with prenatal testosterone level and is the most important factor of prenatal testosterone exposure. Manning has first hypothesized that 2D:4D ratio may predict some disorders, including stuttering and the relationship between 2D:4D and verbal fluency (both phonologically based fluency, the FAS test, and semantically based fluency, the Varley test) and prenatal testosterone. In addition to 2D:4D ratio, Manning defined another finger parameter, DR-L, which is the difference between right and left hand, 2D:4D ratios (Manning, 2002). Besides, the length ratio of the second (index) to the fourth (ring) finger (2D:4D), a putative negative correlate of prenatal $\mathrm{T}$, has become a popular variable for studying effects of prenatal androgenization in humans (Mitsui et al., 2015).

However, 2D:4D may not exclusively reflect prenatal sex hormones but also adult circulating sex hormone levels. Therefore, observed relations between 2D:4D and variables of interest in adults may not reflect effects of prenatal androgenization, as is commonly assumed, but the effects of circulating sex hormones (Manning, 2002).

Stuttering has been linked to left- or mixed-handedness (Mohammadi et al., 2019) and also has been associated to right-hemispheres lateralization for some language processing (Sowman et al., 2014). Hence, it has been speculated that developmental effects of sex hormones like testosterone or estrogen could account for the sex biases in stuttering and underlying neurological mechanism (Suresh et al., 2006). Recently studies have focused on the role of sex steroid in pathophysiology of developmental stuttering. Since few studies report any systematic analysis of the relationships between stuttering and sex hormone and 2D:4D ratio, the current review was conducted in order to analysis the interaction between sex hormone and stuttering, and narrowed the focus. In the present study, we reviewed all previous investigation which directly or indirectly measured the association between post- and pre-natal sex steroid and developmental stuttering.

\section{Method}

A systematic review was conducted using Scopus, Science Direct, PubMed, Medline, Embase, and Cochrane database up to 2020. The search terms include of the following: ("stuttering" [MeSH] OR "stutter") AND ("sex hormone" [MeSH] OR "androgen" OR "2D:4D digit ratio"). A Google Scholar Search was performed, and the first 500 hits were crossed-checked manually to identify pertinent articles that were not detected by the database search. A hand search of the bibliography of articles that met the criteria was conducted to identify additional relevant articles. First, duplicate records were removed, and initial title and abstract screening were conducted for relevance. Records that were clearly not related to stuttering were removed. Second, the abstract or method's sections of records with titles that were ambiguously related to stuttering (e.g., the relation of sex hormone and stuttering) were reviewed, and the record removed if it did not mention stuttering. We used the reference section in the retrieved documents to look for further studies pertaining to our issue. Each article was reviewed independently by the authors. The review process was conducted individually by each author, and the results of the selection were compared. There were no discrepancies in article selection between authors. We will outline areas where the knowledge remains weak and inconclusive, and attempts to further the theoretical knowledge of the intersection of sex hormone and stuttering that could inform practice and guide future research.

\section{Result and Discussion}

We turn to those associations between stuttering, 2D:4D and sex hormones. The Google Scholar search yielded a total of 8,930 titles and the reference list yielded a total of 823 titles. Our review pertains to 21 relationships that met the criteria between putative indicators of prenatal androgenization (left hand 2D:4D, right hand 2D:4D, and measures of circulating levels of sex hormones (total testosterone, bioavailable testosterone, estradiol, luteinizing hormone, follicle-stimulating hormone, and progesterone). Several significant relationships, involving T, FSH, and LH and stuttering were found. The primary findings are listed in Table 1. 
Table 1. Overview of previous studies which investigated associations between sex hormones and stuttering

\begin{tabular}{|c|c|c|c|}
\hline & Study & Number of subjects and the & inding and result \\
\hline 1 & $\begin{array}{l}\text { Dönmez et al., } \\
2019\end{array}$ & $\begin{array}{l}\mathrm{N}=133 \text { ( } 49 \text { boys } \mathrm{CWS} \text { and } \\
84 \text { boys } \mathrm{CWNS}) \\
\text { Age: } 2-12 \text { years } \\
\text { Cross-sectional } \\
\text { case-control study }\end{array}$ & $\begin{array}{l}\text { Left 2D:4D ratio of the patients was significantly higher than that of the control group; } \\
\text { prenatal } \mathrm{T} \text { play a role in the etiology of developmental stuttering }\end{array}$ \\
\hline 2 & $\begin{array}{l}\text { Yuksel et al., } \\
2019\end{array}$ & $\begin{array}{l}\mathrm{N}=130 ; 90 \text { CWS \& } 40 \\
\text { CWNS Age: } 6.8 \pm 3.8 \\
\text { years } \\
\text { Case-control study }\end{array}$ & $\begin{array}{l}\text { Right 2D:4D was significantly lower in stuttering group. } \\
\text { DR-L was significantly lower in stuttering boys than control boys }\end{array}$ \\
\hline 3 & Bilal et al., 2018 & $\begin{array}{l}\mathrm{N}=30 \\
\text { Age: } \leq 18 \\
\text { Prospective case control }\end{array}$ & $\begin{array}{l}\text { The GPER-1 levels of the stuttering patients were found to be higher than those of the } \\
\text { control group and GPER-1 levels of male patients were higher than those of females }\end{array}$ \\
\hline 4 & $\begin{array}{l}\text { Mohammadi et } \\
\text { al., } 2017\end{array}$ & $\begin{array}{l}\mathrm{N}=92 \mathrm{CWS} \text { and } 91 \mathrm{CWNS} \\
\text { Case-control study }\end{array}$ & $\begin{array}{l}\text { T and its metabolites, DHT and estradiol, were significantly higher in CWS } \\
\text { There was a significant positive correlation between T, DHEA and cortisol levels and } \\
\text { stuttering severity } \\
\text { No significant differences in 2D:4D between CWS and CWNS }\end{array}$ \\
\hline 5 & $\begin{array}{l}\text { Selçuk et al., } \\
2015\end{array}$ & $\begin{array}{l}\mathrm{N}=50 \quad(25 \text { CWS and } 25 \\
\mathrm{CWNS}) \\
\text { Age: } 7-12 \text { years } \\
\text { Case-control study }\end{array}$ & $\mathrm{T}$ levels in CWS group were significantly higher than in the control group \\
\hline 6 & $\begin{array}{l}\text { Montag et al., } \\
2015\end{array}$ & $\begin{array}{l}\mathrm{N}=38 \mathrm{CWS}(28 \mathrm{M}-10 \mathrm{~F}) \\
\text { And } \quad 36 \quad \text { CWNS } \\
(24 \mathrm{M}-12 \mathrm{~F}) \\
\text { Age: } 30.63 \text { years } \\
\text { Case-control study }\end{array}$ & $\begin{array}{l}\text { No significant differences in the } 2 \mathrm{D}: 4 \mathrm{D} \text { between } \mathrm{CWS} \text { and CWNS } \\
\text { A significant main effect of sex on the right } 2 \mathrm{D}: 4 \mathrm{D} \text { ratio was observed with males } \\
\text { showing lower ratios compared to women. } \\
\text { 2D:4D correlated negatively with higher scores of the stuttering and this effect was } \\
\text { more pronounced for female persons who stutter. }\end{array}$ \\
\hline
\end{tabular}

CWS: children who stutter; CWDNS: children who do not stutter; 2D:4D: The lengths of index finger (2D) and ring finger (4D) of both hands; D r-l: Right and the left hand 2D:4D ratio; T: testosterone; GPER-1: G-protein coupled membrane estrogen receptor-1; DHT: Dihydrotestosterone; DHEA: Dehydroepiandrosterone.

Stuttering usually begins between the ages of 2 and 5 years, and it is seen two times further frequently in boys in this age group, while the ratio changes in the adult age group, occurring up to four times more in the male sex because of that $\mathrm{T}$, which is a sex hormone, might play a role in the etiology and chronicity of the disease. $\mathrm{T}$ regulates cell death and dopamine transport in the substantia nigra and striatum (Selçuk et al., 2015). It has been shown that changes occurring in the sex steroids during adolescence play an important role in dopamine signaling and regulation (Selçuk et al., 2015). T may impact upon the disease in this way. Indeed, the role of $T$ in the diseases where dopamine and the basal ganglia play important roles (Parkinson's, TS, dystonia, etc) have been studied (Whitehouse et al., 2009). The role of stress on the triggering of stuttering is well known. Stress factors play a particular role in the triggering of acquired stuttering; also, stuttering is a stress factor in itself, so this vicious cycle has been reported to lead to chronicity in stuttering (Ortega \& Ambrose., 2011). Stress activates the hypothalamo-pituitary-adrenal (HPA) axis and, consequently, a hormonal axis that includes T (HPA) is activated by stress. Thus, the stress that arises during stuttering activates the HPA axis and it can be concluded that serum T levels can increase during stuttering (Ortega \& Ambrose, 2011).

Schachter (1994) investigated the prevalence of non-right handedness in a group of women whose mothers had been administered diethyl-stilbestrol (DES) during their pregnancies. DES is a synthetic estrogen, administered to prevent miscarriage, which affects the fetal brain in a similar fashion as T (Schachter, 1994). Montag et al. revealed that there was no significant relationship between prenatal T (2D:4D) and stuttering (Montag et al., 2015). Moreover, Mohammadi et al., showed no significant relationship between prenatal T (2D:4D) and stuttering (Mohammadi et al., 2017).

On the other hand, Martel et al showed that high prenatal $\mathrm{T}$ exposure may make males more sensitive to environmental stressors, compared to females, potentially by slowing down fetal growth in order to calibrate a phenotype so that it will be well-suited for coping with these early-childhood environmental conditions (Martel \& Roberts., 2014). Moreover, Lust et al reveals that $\mathrm{T}$ affects different brain structures in males and females and 
modulates heritable variation of human lateralization (Lust et al., 2010). Besides, Wang et al revealed that a higher prenatal $\mathrm{T}$ exposure was correlated with a greater risk of developing disruptive behavior disorders, and $\mathrm{T}$ may exert differential neurocognitive effects between boys and girls (Wang et al., 2017). Mohammadi et al., showed that postnatal serum levels of testosterone and its metabolites, dihydrotestosterone and estradiol, were significantly higher in child who stuttered compared to child who did not stutter. They also found a significant positive correlation between postnatal testosterone, dehydroepiandrosterone and cortisol levels and stuttering severity (Mohammadi et al., 2017).

Manning investigated the relationship between 2D:4D finger ratio (both right and left hand) and testicular function in men attending an infertility clinic and in men included from the UK general population. They found a direct association between the 2D:4D finger ratio and the FSH and LH respectively, and an inverse association with T level and testis volume in men with compromised testicular function, but not in men with normal testicular function (Manning et al., 2004). The relationship between 2D:4D and prenatal T and estrogen exposure level was first discussed in detail by Manning et al. 2D:4D values were found to be about 25 standard deviations higher than male values (Manning et al., 1998). On the other hand, Montag et al. studied 2D:4D ratio in adults who stutter and reported that there was no significant difference in $2 \mathrm{D}: 4 \mathrm{D}$ ratio between stuttering adults and healthy controls; however, they also found that low 2D:4D was associated with higher negative experiences due to stuttering, particularly in females (Montag et al., 2015). Additionally, growth of the adrenal gland has been found to increase prenatal androgen levels and cause a low 2D:4D ratio in children with congenital adrenal hyperplasia. Besides, they found that 2D:4D ratio of the right hand was significantly lower in the stuttering group compared to those who do not, which supports a higher level of prenatal T exposure in CWS. Besides, right hand 2D:4D and DR-L were significantly lower both in 'severe' and 'mild-to-moderate' stuttering groups compared to the controls and higher level of fetal $\mathrm{T}$ exposure has been accused to play an important role in the etiology of stuttering (Yuksel et al., 2019).

On the other hand, Donmez et al reported that the left 2D:4D ratio of the patients was significantly higher than that of the control group $(\mathrm{p}=0.017)$ and there was no significant statistical difference between the groups in terms of right 2D:4D ratios ( $p=0.595)$ (DÖNMEZ et al., 2019). Moreover, Selçuk et al revealed that he medians of the testosterone levels of the stutterer were significantly higher than in the control group $(\mathrm{P}=0.001)$. Besides, there was a significant correlation between the severity of the stuttering and testosterone levels in the stutterer group ( $\mathrm{P}=0.0001$ ) (Selçuk et al., 2015).

Besides, Beaton et al demonstrated that the 2D:4D ratio of neither the left nor the right hand was connected to handedness, the distinction between the digit ratios of the right and left hands, DR-L, was a significant forecaster of handedness and of the performance difference between the hands on a peg-moving task. Circulating $\mathrm{T}$ levels did not foretell the digit ratio of the left or right hand; nor was there a significant relationship between concentrations of salivary T (or cortisol) and either hand preference or asymmetry in manual skill. It can be concluded that the association between DR-L and hand preference arises because DR-L is a correlate of sensitivity to $\mathrm{T}$ in the developing fetus. (Beaton et al., 2011).

However, Hollier demonstrated that there was no significant associations between digit ratio and any androgen or estrogen concentrations considered separately the testosterone to estradiol ratio, total androgen bioactivity measure or ratio of androgen to estrogen bioactivity (all $p>.05$ ) and total estrogen bioactivity was negatively correlated with left hand digit ratio $(\mathrm{r}=-.172, \mathrm{p}=.02)$. It shows that digit ratio is not related to fetal androgens or estrogens at late gestation (Hollier et al., 2014). Ho"nnekopp studied 102 males and 66 females and found no association between blood serum T levels and digit ratio (Hönekopp et al., 2006). On the other hand, Ju"rima"e et al. reported a significant correlation (uncorrected for multiple testing) in 26 male adolescents between serum $\mathrm{T}$ levels and right hand 2D:4D ratio (measured from wrist to fingertip) (Jürimäe et al., 2008). Moreover, Moffat and Hampson who, using a binary classification of handedness, reported that 40 adult left-handers showed significantly lower concentrations of salivary T than 40 right-handers (Moffat \& Hampson, 1996).

Firman et al. (2003) found no significant association between 2D:4D ratios and measures of semen quality, neither for right nor left hands. However, they did find a momentous inverse association between body asymmetry (i.e. subtracting the left from the right-side values of the ear, wrist, elbow, ankle and foot) and sperm count as well as sperm motility (Firman et al., 2003). Manning et al. (1998) have found a direct significant association between the finger ratios of $2 \mathrm{D}: 4 \mathrm{D}$ of the right hand and $\mathrm{LH}$, prolactin, and estrogen level respectively, and a reversed association between the finger ratio and the $\mathrm{T}$ levels. Besides, they also found a statistically significant inverted association with sperm count but no significant association between the 2D:4D finger ratios and the FSH level (Manning et al., 1998). 
Hickey et al. correlated maternal and rostenedione (A4), dehydroepiandrosterone sulfate (DHEAS), sex hormone binding globulin (SHBG), total testosterone (TT), free testosterone (cFT) and free androgen index (FAI) measured at 18 and 34 weeks' gestation with offspring digit ratio variables measured at 14-16 years of age. Other than weak positive correlations with A4 at 18 weeks, no effects were observed (Hickey et al., 2010). On the other hand, Ventura et al manifested that the 2D:4D dimorphism is already current at birth. As expected, males had lower mean 2D:4D ratio than females. Richard et al establish that the distinction is subtle and there is a large convergence of 2D:4D distributions between sexes (Ventura et al., 2013).

Several studies have reported on associations between digit ratio and fetal hormones measured from amniotic fluid. Lutchmaya et al. observed a significant negative correlation between the ratio of testosterone to estradiol in amniotic fluid and R2D:4D in two-year-old infants. However, no effect was observed for L2D:4D, and neither testosterone nor estradiol was a significant predictor on its own (Lutchmaya et al. 2004). Ventura et al. reported a significant negative correlation between amniotic testosterone and L2D:4D in newborn infants, though a similar effect for R2D:4D was not statistically significant; there were no correlations between amniotic testosterone and right or left 2D:4D in newborns (Ventura et al., 2013).

It is not immediately obvious why the difference between digit ratios of left and right hands should predict anything. Nonetheless, the effect we report was statistically highly significant. Conceivably the relative length of the index and ring fingers is related to manual "deftness" or dexterity; the larger the 2D:4D ratio, the more deft or dextrous the hand, the more deft or dextrous hand being the one that is preferred. If so, an increasing 2D:4D ratio of one hand relative to that of the other would be associated with an increasing preference for the hand with the larger ratio. One might note in this connection that generally the 2D:4D ratio is larger in females than in males, and that females tend to be better than males at tasks involving fine motor skills, although this may be an artefact of finger diameter (Peters \& Campagnaro, 1996).

One conclusion derived from the review of the literature is that much of the past research does not yet fit under a comprehensive theoretical umbrella. Future work will benefit from expansion, elaboration, and clarification of theoretical models and clarification of issues important for subtyping.

\section{Conflict of interests}

The authors declare that there is no conflict of interests regarding the publication of this paper.

\section{References}

Al-Zaid, F. S., Alhader, A. A., \& Al-Ayadhi, L. Y. (2015). The second to fourth digit ratio (2D: 4D) in Saudi boys with autism: A potential screening tool. Early Human Development, 91(7), 413-5.

Apicella et al. (2008). Testosterone and financial risk preferences. Evolution and Human Behavior, 29(6), 384-390.

Bahrun, S., As' ad, S., Sinrang, W., Patellongi, I., Taherong, F., \& Mappaware, N. A. (2019). The Role of CYP17 Gene Expression towards Imbalance of Estrogen and Progesterone Hormones at Luteal Phase in Marriageable Girls. Indian Journal of Public Health Research \& Development, 10(1), 1135-41.

Baron-Cohen, S., Lutchmaya, S., \& Knickmeyer, R. (2004). Prenatal testosterone in mind. MIT Press, Cambridge, MA.

Barrett-Connor, E., Goodman-Gruen, D., \& Patay, B. (1999). Endogenous sex hormones and cognitive function in older men. J Clin Endocrinol Metab, 84(10), 3681-3685.

Beaton, A. A., Rudling, N., Kissling, C., Taurines, R., \& Thome, J. (2011). Digit ratio (2D: 4D), salivary testosterone, and handedness. Laterality, 16(2), 136-55.

Berenbaum, S. A., Korman Bryk, K., Nowak, N., Quigley, C. A., \& Moffat, S. (2009). Fingers as a marker of prenatal androgen exposure. Endocrinology, 150, 5119-5124.

Bilal, N., Kurutas, E. B., \& Orhan, I. (2018). An evaluation of G-protein coupled membrane estrogen receptor-1 level in stuttering. European Archives of Oto-Rhino-Laryngology, 275(2), 469-476.

Burriss, R. P., Little, A. C., \& Nelson, E. C. (2007). 2D: 4D and sexually dimorphic facial characteristics. Archives of Sexual Behavior, 36(3), 377-84.

Burton, L. A., Henninger, D., \& Hafetz, J. (2005). Gender differences in relations of mental rotation, verbal fluency, and SAT scores to finger length ratios as hormonal indexes. Developmental Neuropsychology, 28(1), 493-505. 
Christensen, J. M., \& Sacco, P. R. (1989). Association of hair and eye color with handedness and stuttering. Journal of Fluency Disorders, 14(1), 37-45.

Ciumas, C., Lindén Hirschberg, A., \& Savic, I. (2008). High fetal testosterone and sexually dimorphic cerebral networks in females. Cereb Cortex, 19, 1167-1174.

Cohen-Bendahan, C. C, Buitelaar, J. K., van Goozen, S. H., \& Cohen-Kettenis, P. T. (2004). Prenatal exposure to testosterone and functional cerebral lateralization: A study in same-sex and opposite-sex twin girls. Psychoneuroendocrinology, 297, 911-916

Cohen-Bendahan, C. C. C., van de Beek, C., \& Berenbaum, S. A. (2005). Prenatal sex hormone effects on child and adult sex-typed behavior: methods and findings. Neurosci Biobehav Rev., 29, 353-384.

Collaer, M. L., \& Hines, M. (1995). Human behavioral sex differences: a role for gonadal hormones during early development?. Psychological Bulletin, 118(1), 55.

Coolican, J., \& Peters, M. (2003). Sexual dimorphism in the 2D/4D ratio and its relation to mental rotation performance. Evolution and Human Behavior, 24(3), 179-183.

de Oliveira, C. M. C., Cunha, D., \& dos Santos, A. C. (2013). Risk factors for stuttering in disfluent children with familial recurrence. Domingues CE.

Dönmez et al. (2019). The relationship between prenatal testosterone and developmental stuttering in boys. The Turkish Journal of Pediatrics, 61(2), 193-199.

Drayna, D., Kilshaw, J., \& Kelly, J. (1999). The sex ratio in familial persistent stuttering. American Journal of Human Genetics, 65(5), 1473.

Firman, R. C., Simmons, L. W., Cummins, J. M., \& Matson, P. L. (2003). Are body fluctuating asymmetry and the ratio of 2 nd to 4 th digit length reliable predictors of semen quality? Human Reproduction, 18(4), $808-12$.

Geschwind, N., \& Galaburda, A. M. (1987). Cerebral lateralization: Biological mechanisms, associations, and pathology. MIT press.

Gordon, N. (2002). Stuttering: incidence and causes. Dev Med Child Neurol, 44, 278-282.

Götestam, K. O., Coates, T. J, \& Ekstrand, M. (1992). Handedness, dyslexia and twinning in homosexual men. International Journal of Neuroscience, 63(3-4), 179-86.

Grainger, K., Cheng, H., Moretti-Ferreira, D., Riazuddin, S., \& Drayna, D. (2017). Are variants in sex hormone metabolizing genes associated with stuttering?. Language, 175, 47-56.

Grimshaw, G. M., Bryden, M. P., \& Finegan, J. A. K. (1995). Relations between prenatal testosterone and cerebral lateralization in children. Neuropsychology, 9, 68-79.

Hedges, L. V., \& Nowell, A. (1995). Sex-differences in mental test-scores, variability, and numbers of high-scoring individuals. Science, 269(5220), 41-45.

Hickey et al. (2010). Maternal and umbilical cord androgen concentrations do not predict digit ratio $(2 D: 4 D)$ in girls: a prospective cohort study Psychoneuroendocrinology, 35, 1235-1244.

Hollier, L. (2014). Fetal testosterone exposure and its relationship to the development of language and cerebral laterality (Doctoral dissertation). University of Western Australia: School of Psychology and Telethon Kids Institute.

Hollier, L. P., Keelan, J. A., Hickey, M., Maybery, M. T., \& Whitehouse, A. J. O. (2014). Measurement of androgen and estrogen concentrations in cord blood: accuracy, biological interpretation, and applications to understanding human behavioral development. Front Endocrinol, 5.

Hollier, L. P., Keelan, J. A., Jamnadass, E. S., Maybery, M. T., Hickey, M., \& Whitehouse, A. J. (2015). Adult digit ratio (2D: 4D) is not related to umbilical cord androgen or estrogen concentrations, their ratios or net bioactivity. Early Human Development, 91(2), 111-7.

Hollier, L. P., Maybery, M. T., Keelan, J. A., Hickey, M., \& Whitehouse, A. J. (2014). Perinatal testosterone exposure and cerebral lateralization in adult males: evidence for the callosal hypothesis. Biol Psychol, 103, 48-53. 
Hönekopp, J., Manning, J. T., \& Müller, C. (2006). Digit ratio (2D: 4D) and physical fitness in males and females: Evidence for effects of prenatal androgens on sexually selected traits. Hormones and Behavior, 49(4), 545-549.

Howard, J. M. (2004). Testosterone and psychosis. Br J Psychiatry, 185, 173.

Hyde, J. S. (2005). The gender similarities hypothesis. American Psychologist, 60(6), 581-592.

Hyde, J. S., \& Linn, M. C. (1988). Gender differences in verbal ability: A meta-analysis. Psychological Bulletin, 104(1), 53.

Jørgensen, N., Bang, A. K., Carlsen, E., Holm, M., Petersen, J. H., \& Skakkebæk, N. E. (2006). Reply: A study of finger lengths, semen quality and sex hormones in 360 young men from the general Danish population. Human Reproduction, 21(5), 1331-2.

Jürimäe, T., Voracek, M., Jürimäe, J., Lätt, E., Haljaste, K., Saar, M., \& Purge, P. (2008). Relationships between finger-length ratios, ghrelin, leptin, IGF axis, and sex steroids in young male and female swimmers. European Journal of Applied Physiology, 104(3), 523.

Karimi, H., \& Nilipour, R. E. Z. A. (2011). Characteristics of developmental stuttering in Iran. Multilingual Aspects of Fluency Disorders, 5, 205-207.

Kartalci, Ş. (2010). Testosterone and depression. Current Approaches Psychiatry, 2(4), 457-472.

Kartalci, S., Erbay, L. G., Özcan, Ö. Ö., Yüksel, T., \& Ünal, S. (2012). Testosteron alimi sonrasi baslayan kekemelik: Bir olgu sunumu/Stuttering after testosterone administration: A case report. Anadolu Psikiyatri Dergisi, 13(1), 82.

Kasbi et al. (2015). Effects of stuttering on quality of life in adults who stutter. Middle East Journal of Rehabilitation and Health, 2, 1.

Lust, J. M., Geuze, R. H., Van de Beek, C., Cohen-Kettenis, P. T., Groothuis, A. G. G., \& Bouma, A. (2010). Sex specific effect of prenatal testosterone on language lateralization in children. Neuropsychologia, 48, 536-540.

Lutchmaya, S., Baron-Cohen, S., Raggatt, P., Knickmeyer, R., \& Manningm, J. T. (2004). 2nd to 4th digit ratios, fetal testosterone and estradiol. Early Hum Dev., 77, 23-28.

Manning, J. T. (2002). Digit ratio. A pointer to fertility, behaviour, and health. New Brunswick, NJ: Rutgers University Press.

Manning, J. T. (2011). Resolving the role of prenatal sex steroids in the development of digit ratio. Proc Natl Acad Sci U S A., 108, 16143-16144.

Manning, J. T., Kilduff, L. P., \& Trivers, R. (2013). Digit ratio (2D:4D) in Klinefelter's syndrome. Andrology, 1, 94-99.

Manning, J. T., Kilduff, L., Cook, C., Crewther, B., \& Fink, B. (2014). Digit ratio (2D:4D): A biomarker for prenatal sex steroids and adult sex steroids in challenge situations. Front Endocrinol, 5.

Manning, J. T., Scutt, D., Wilson, J., \& Lewis-Jones, D. I. (1998). The ratio of 2nd to 4th digit length: A predictor of sperm numbers and concentrations of testosterone, luteinizing hormone and oestrogen. Human Reproduction (Oxford, England), 13(11), 3000-4.

Manning, J. T., Wood, S., Vang, E., Walton, J., Bundred, P. E., Van Heyningen, C., \& Lewis-Jones, D. I. (2004). Second to fourth digit ratio (2D: 4D) and testosterone in men. Asian Journal of Andrology, 6(3), 211-6.

Martel, M. M., \& Roberts, B. A. (2014). Prenatal testosterone increases sensitivity to prenatal stressors in males with disruptive behavior disorders. Neurotoxicology and Teratology, 44, 11-7.

Migeon, C. J., \& Wisniewski, A. B. (1998). Sexual differentiation: From genes to gender. Hormone Research in Paediatrics, 50(5), 245-251.

Mitsui et al. (2015). Effects of prenatal Leydig cell function on the ratio of the second to fourth digit lengths in school-aged children. PLoS One, 10, e0120636.

Moffat, S. D., \& Hampson, E. (1996). A curvilinear relationship between testosterone and spatial cognition in humans: possible influence of hand preference. Psychoneuroendocrinology, 21(3), 323-37.

Mohammadi, H., \& Papadatou-Pastou, M. (2019). Cerebral laterality as assessed by hand preference measures and developmental stuttering. Laterality: Asymmetries of Body, Brain and Cognition, 1-23. 
Mohammadi, H., \& Papadatou-Pastou, M. (2019). Cerebral laterality as assessed by hand preference measures and developmental stuttering. Laterality: Asymmetries of Body, Brain and Cognition, 24, 1-23.

Mohammadi, H., Bakhtiar, M., Rezaei, M., \& Sadeghi, K. (2012). Stuttering behavior in Kurdish-Persian bilingual speakers. Procedia-Social and Behavioral Sciences, 32, $283-7$.

Mohammadi, H., Joghataei, M. T., Rahimi, Z, Faghihi, F., Khazaie, H., Farhangdoost, H., \& Mehrpour, M. (2017). Sex steroid hormones and sex hormone binding globulin levels, CYP17 MSP AI (- 34 T: C) and CYP19 codon 39 (Trp: Arg) variants in children with developmental stuttering. Brain and Language, 175, 47-56.

Mohammadi, H., Nilipur, R., \& Yadegari, F. (2010). Prevalence of Stuttering in Kurdish-Persian Consecutive Bilinguals in Iran. Asia Pacific Journal of Speech, Language and Hearing, 13(4), 235-241.

Montag, C., Bleek, B., Breuer, S., Prüss, H., Richardt, K., Cook, S., Yaruss, J. S., \& Reuter, M. (2015). Prenatal testosterone and stuttering. Early Human Development, 91(1), 43-6.

Neufang et al. (2009). Sex differences and the impact of steroid hormones on the developing human brain. Cerebral Cortex, 19(2), 464-473.

Nning, J. T., \& Fink, B. (2017). Are there any "direct" human studies of digit ratio (2D:4D) and measures of prenatal sex hormones? Early Hum Dev., 113, 73-74.

Ortega, A. Y., \& Ambrose, N. G. (2011). Developing physiologic stress profiles for school-age children who stutter. Journal of Fluency Disorders, 36(4), 268-73.

Peters, M., \& Campagnaro, P. (1996). Do women really excel over men in manual dexterity? Journal of Experimental Psychology: Human Perception and Performance, 22(5), 1107.

Prasse, J. E., \& Kikano, G. E. (2008). Stuttering: An overview. Am Fam Physician, 77, 1271-1276.

Redmond, S. M., \& Ash, A. C. (2017). Associations between the 2D: 4D proxy biomarker for prenatal hormone exposures and symptoms of developmental language disorder. Journal of Speech, Language, and Hearing Research, 60(11), 3226-36.

Redmond, S. M., \& Ash, A. C. (2017). Associations between the 2D: 4D proxy biomarker for prenatal hormone exposures and symptoms of developmental language disorder. Journal of Speech, Language, and Hearing Research, 60(11), 3226-36.

Reilly, D. (2012). Gender, culture, and Sex-typed cognitive abilities. PLoS ONE, 7(7), e39904.

Ribeiro, E., Neave, N., Morais, R. N., \& Manning, J. T. (2016). Direct versus indirect measurement of digit ratio (2D:4D): a critical review of the literature and new data. Evol Psychol, 14.

Saino, N., Rubolini, D., Romano, M., \& Boncoraglio, G. (2007). Increased egg estradiol concentration feminizes digit ratios of male pheasants (Phasianus colchicus). Naturwissenschaften, 94, 207-212.

Sato et al. (2011). Functional lateralization of speech processing in adults and children who stutter. Front Psychol, 27, 70.

Schachter, S. C. (1994). Handedness in women with intrauterine exposure to diethylstilbestrol. Neuropsychologia, 32(5), 619-23.

Selçuk, E. B., Erbay, L. G., Özcan, Ö. Ö., Kartalci, Ş., \& Batcioğlu, K. (2015). Testosterone levels of children with a diagnosis of developmental stuttering. Therapeutics and Clinical Risk Management, 11, 793.

Smail, P. J., Reyes, F. I., Winter, J. S. D., \& Faiman, C. (1981). The fetal hormonal environment and its effect on the morphogenesis of the genital system. In Pediatric andrology (pp. 9-19). Springer, Dordrecht.

Smith, A., \& Weber, C. (2017). How stuttering develops: The multifactorial dynamic pathways theory. Journal of Speech, Language, and Hearing Research, 60(9), 2483-505.

Sowman, P. F., Crain, S., Harrison, E., \& Johnson, B. W. (2014). Lateralization of brain activation in fluent and non-fluent preschool children: A magnetoencephalographic study of picture-naming. Frontiers in Human Neuroscience, 8, 354.

Steiner, M., Dunn, E., \& Born, L. (2003). Hormones and mood: From menarche to menopause and beyond. $J$ Affect Disord, 74(1), 67-83. 
Suresh, R., Ambrose, N., Roe, C., Pluzhnikov, A., Wittke-Thompson, J. K., Ng, M. C., Wu, X., Cook, E. H., Lundstrom, C., Garsten, M., \& Ezrati, R. (2006). New complexities in the genetics of stuttering: significant sex-specific linkage signals. The American Journal of Human Genetics, 78(4), 554-63.

Talarovičová, A., Kršková, L., \& Blažeková, J. (2009). Testosterone enhancement during pregnancy influences the 2D:4D ratio and open field motor activity of rat siblings in adulthood. Horm Behav, 55, 235-239.

Teatero, M. L., \& Netley, C. (2013). A critical review of the research on the extreme male brain theory and digit ratio (2D:4D). J Autism Dev Disord, 43, 2664-2676.

Van de Beek, C., Thijssen, J. H. H., Cohen-Kettenis, P. T., van Goozen, S. H. M., \& Buitelaar, J. K. (2004). Relationships between sex hormones assessed in amniotic fluid, and maternal and umbilical cord serum: What is the best source of information to investigate the effects of fetal hormonal exposure? Horm Behav, 46, 663-669.

Van Hemmen, J., Cohen-Kettenis, P. T., Steensma, T. D., Veltman, D. J., \& Bakker, J. (2017). Do sex differences in CEOAEs and 2D:4D ratios reflect androgen exposure? A study in women with complete androgen insensitivity syndrome. Biol Sex Diff, 8 .

Ventura, T., Gomes, M. C., Pita, A., Neto, M. T., \& Taylor, A. (2013). Digit ratio (2D:4D) in newborns: influences of prenatal testosterone and maternal environment. Early Hum Dev., 89, 107-112.

Voracek, M. (2008). Digit ratio (2D:4D) as a marker for mental disorders: low (masculinized) 2D:4D in autism-spectrum disorders, high (feminized) 2D:4D in schizophrenicspectrum disorders. Behav Brain Sci., $31,283-28$.

Wang, L. J., Chou, M. C., Chou, W. J., Lee, M. J., Lee, S. Y., Lin, P. Y., Lee, Y. H., Yang, Y. H., \& Yen, C. F. (2017). Potential role of pre-and postnatal testosterone levels in attention-deficit/hyperactivity disorder: is there a sex difference? Neuropsychiatric Disease and Treatment, 13, 1331.

Whitehouse, A. J., Watt, H. J., Line, E. A., \& Bishop, D. V. (2009). Adult psychosocial outcomes of children with specific language impairment, pragmatic language impairment and autism. International Journal of Language \& Communication Disorders, 44(4), 511-28.

Witelson, S. F., \& Nowakowski, R. S. (1991). Left out axoms make men right: A hypothesis for the origin of handedness and functional asymmetry. Neuropsychologia, 29(4), 327-33.

Wu, J. C., Maguire, G., Riley, G., Lee, A., Keator, D., Tang, C., Fallon, J., \& Najafi, A. (1997). Increased dopamine activity associated with stuttering. Neuroreport, 8(3), 767-70.

Yuksel, T., Sizer, E., \& Durak, H. (2019). 2D: 4D ratios as an indicator of intrauterine androgen exposure in children who stutter. Early Human Development, 135, 27-31.

Zitzmann, M. (2006). Testosterone and the brain. Aging Male, 9(4), 195-199.

\section{Copyrights}

Copyright for this article is retained by the author(s), with first publication rights granted to the journal.

This is an open-access article distributed under the terms and conditions of the Creative Commons Attribution license (http://creativecommons.org/licenses/by/4.0/). 